\title{
A Longitudinal Study of Knowledge, Attitudes and Self-Efficacy in Pregnant Asthmatics
}

\author{
Nancy J. MacMullen ${ }^{1}$, Sharon Telleen ${ }^{2}$, Mahmoud Ismail ${ }^{3}$, Linda F. Samson ${ }^{1}$, Phyllis Jones ${ }^{1}$ \\ ${ }^{1}$ Governors State University, University Park, USA \\ ${ }^{2}$ University of Illinois at Chicago, Chicago, USA \\ ${ }^{3}$ Maternal-Fetal Medicine, University of Chicago, Chicago, USA \\ Email: nmacmullen@govst.edu \\ Received 26 April 2013; revised 31 August 2013; accepted 5 November 2013 \\ Copyright (C) 2013 Nancy J. MacMullen et al. This is an open access article distributed under the Creative Commons Attribution Li- \\ cense, which permits unrestricted use, distribution, and reproduction in any medium, provided the original work is properly cited.
}

\section{ABSTRACT}

The objectives of this study of pregnant women with asthma are 1) to describe their knowledge and attitudes of asthma in pregnancy and their self-efficacy in carrying out their self-management plan during pregnancy, 2) to determine if their knowledge, attitudes, and self-efficacy changed as their pregnancy progressed, and 3) to ascertain the relationship between knowledge, attitudes, and self-esteem and age, education, trimester of pregnancy, weeks of pregnancy, the number of times pregnant and live births. Sixty-eight pregnant women who had an asthma diagnosis were given knowledge, attitudes and self-efficacy questionnaires initially during the point of first contact (first or second) trimester (Time I) and subsequently during the latter part of their pregnancy (third trimester) (Time II). A demographic data form was also administered at Times I and II. Data were collected in an urban academic medical clinic and analyzed using SPSS 17. Data analysis utilized frequencies, paired samples $t$ tests, and linear regression. There were no significant differences between Time I and Time II in attitudes and self-efficacy. Significant differences were limited to the knowledge questionnaire $(t=4.370, p=0.05)$. There was a significant relationship between education and knowledge. Pregnant women with asthma had gaps in their knowledge of asthma in pregnancy, although their knowledge increased as their pregnancy progressed from Time I to Time II. Also, the more education the women had, the better they understood asthma. Education for pregnant women with asthma is tailored to their needs and modified as necessary. Nurses are prepared to address this challenge.

${ }^{*}$ Funded by NIH Grant \#5P20MD001816-05.
Keywords: Asthma; Pregnancy Complications; Knowledge; Attitudes; Self-Efficacy

\section{INTRODUCTION}

Asthma is a major public health concern [1]. Authorities have estimated that there are more than 100 million asthma sufferers worldwide including 22 million Americans $[2,3]$. Asthma affects people of all races, both sexes, and all ages in every region of the USA [4]. The incidence of asthma is particularly high among poor, African-American and urban inner city residents $[5,6]$. Asthma attack prevalence is higher in children aged less than 18 years of age $(8.5 \%)$ than in the adult population, $(6.7 \%)$. The prevalence is higher in blacks compared to whites [7].

In addition to the troubling and often life-threatening symptoms experienced by children, adults, and minorities, asthma affects $8.4 \%$ to $8.8 \%$ percent of pregnancies, making it one of the commonest medical complications of pregnancy [8]. While well-controlled asthma poses little to no risk to the fetus and mother, uncontrolled asthma during pregnancy has been associated with premature delivery, low birth weight, fetal death, pregnancy induced hypertension, hyperbilirubinemia, and an increased rate of delivery by cesarean section [9-12].

\section{PROBLEM/PURPOSE}

Because asthma and pregnancy can cause morbidity and mortality for both the mother and fetus/neonate, it is an important topic for research. The research on asthma in pregnancy has focused on diagnosis and treatment (primarily pharmaco-therapeutics). However the effectiveness of these treatments is dependent upon both the woman's knowledge and understanding of asthma during pregnancy and her ability to carry out the asthma self- 
management plan.

There is a wealth of literature that describes effective educational programs, knowledge about asthma management, attitudes toward asthma and self-efficacy for nonpregnant adults and children [13-16]. However, research on these issues for pregnant women is limited. Only a few studies address these issues [17]. Research in this area is especially important since controlling asthma during pregnancy significantly reduces the risk to the fetus and the mother. The purpose of this study of pregnant women with asthma is three fold: 1) to describe their knowledge and attitudes of asthma in pregnancy and their self-efficacy in carrying out their self-management plan during pregnancy, 2) to determine if their knowledge, attitudes, and self-efficacy changed as their pregnancy progressed, and 3) ascertain the relationship between knowledge, attitudes, and self-esteem and age, education, trimester of pregnancy, weeks of pregnancy, the number of times pregnant and live births.

\section{REVIEW OF LITERATURE}

Success of any medical regimen (including the regimen for asthma) requires consideration of three patient variables: knowledge, attitude and self-efficacy. When the interaction of these variables occurs, it is more likely that the asthma treatment is effective. Knowledge enables the patient to perform the appropriate procedures to control symptoms (peak flow meters, medication administration, avoiding asthma triggers). Attitude more specifically refers to how a patient feels toward illness and her willingness to work with her health care providers to manage her asthma. Self-efficacy refers to the patient's confidence in her ability to contribute to the management of asthma [18].

\subsection{Knowledge}

There are many review articles in which asthma education for pregnant women is recommended. Several researchers state that asthma education for pregnant women is an essential component of asthma management [19-24]. Patient education aids in reassuring the women about their fears of the effects of asthma on themselves and their fetus, as well as providing the knowledge for self-management. Powrie, Larson, \& Miller state that patients should receive pre-conceptual education about maintenance and rescue medications, measurement of PEFR, the proper use of inhalers, asthma prevention and adherence to an asthma action plan [25].

\subsection{Attitudes}

Little research has been done to evaluate the impact of attitudes on asthma management/self-care. The majority of studies have been conducted on adult non-pregnant asthmatics. Richardson examined the perceived learning needs to manage the associated health problems in young adults with asthma [26]. In her study, she described the psychosocial aspect of asthma, some of which reflect a negative attitude toward the disease in her patient population. The sample consisted of 40 Canadians between the ages of 20 and 45 years old. Thirty-eight percent acknowledged that they experienced very unpleasant emotions and feelings with asthma causing frustration, anger, and resentment. "Scary" was how another individual described severe episodes. Another 30\% stated that it was difficult to accept that they were diagnosed with a chronic illness. Forty-five percent said that they were embarrassed by asthma symptoms or by taking medication for asthma in public.

Beckmann surveyed over 300 women regarding their perceptions of their asthma during pregnancy [27]. One of the questions in the survey asked about emotional issues that the women experienced during their pregnancy. Responses indicated that the worry was a significant emotional response. Effects of medication on the baby and how an asthma attack affected the baby was of particular concern.

It is well known that psychological factors play an important role in asthma symptomatology and management with non-pregnant patients [28,29]. How attitudes affect asthma management in pregnant women needs to be researched to determine their impact.

\subsection{Self-Efficacy}

Confidence in one's ability to successfully execute specific behaviors is known as self-efficacy. Self-efficacy is an essential component of self-management or self-care and affects asthma patients' abilities to be effective selfmanagers [30]. Self-efficacy in health care has been defined as "control over specific behaviors necessary in handling an illness" [31]. Aligned to self-efficacy is selfmanagement [32]. Self-management is used to describe the process whereby asthmatic patients make changes to their treatment in response to recognized changes in the severity of their symptoms in accordance with predetermined guidelines. When patients fail at self-management, and fail to adhere to treatment regimens, it is often not known whether the patients' noncompliance is due to an uncooperative attitude or to lack of self confidence in their ability to self-manage.

Shegog, et al. examined the effect of a theory based application of a computerized educational program for pediatric asthma self-management education [33]. This experimental pre-test, post- test study utilized gaming as the computer format. Children in both the control and the experimental group had positive impressions of the program and the intervention group showed significant improvement in self-efficacy when an outlier score was 
omitted.

In a systematic review of literature on sex and gender role and self-regulation on pregnant women with asthma. Clark, Valerio, \& Gong found that incorporating sex and gender role influences in self-regulation education had a positive effect on their ability to manage asthma [34]. The authors call for more evidence-based asthma education interventions to help women with their asthma selfmanagement challenges.

Murphy, Gibson, Talbot, Kessell and Clifton investigated asthma self-management skills and knowledge in a group of pregnant women with mild, moderate, and severe asthma [17]. The study participants were given an educational intervention. The content included asthma control and management skillsand counseling where appropriate. The results of their study, demonstrated that there was an improvement in management skills after the intervention. In patients who had severe asthma, there was a significant decrease in the percentage of patients who were non-adherent to medication. Among mild, moderate and severe asthmatics there were significant increases in the proportion of patients with medication

The self-efficacy of pregnant patients with asthma has rarely been studied. Scientific inquiryhas been focused on self-management, of which self-efficacy is a significant part [35]. Research needs to be conducted that will reveal how confident asthma patients are regarding their self-management of asthma, now that they are pregnant.

\subsection{Summary}

As previous research results have indicated, asthma education knowledge, attitudes and self-efficacy are qualities that are essential for patients with chronic disease to be able to care for themselves in collaboration with health care providers. These three qualities are intertwined in fostering the success of the medical regime necessary for asthma control. There needs to be more research into the relationship of these variables and their impact on pregnant women with asthma.

\section{THEORETICAL FRAMEWORK}

Self-care agency, or responsibility for self-care activities, is the power to know and meet the demands for management of their care, and is the cornerstone of Dorothea Orem's Self-Care Deficit Nursing Theory. According to Orem, self-care behaviors are made up of deliberate actions individuals select and perform in sequence to meet self-care needs [36]. It is the focus of nursing to identify where the patient and family cannot practice self-care and aim to meet these self-care deficits. Self-care practice is dependent upon the patient's judgment of whether he/she can perform the measures. This is particularly important for a pregnant patient with asthma. By finding out what the patient knows about asthma, and what she wants to know adherence is improved and the incidences of acute episodes are reduced.

\section{RESEARCH QUESTIONS}

The study was designed to address the following research questions:

1) How knowledgeable are pregnant women with asthma about asthma in pregnancy?

2) What are the attitudes toward asthma in pregnancy of pregnant women with asthma?

3) What is the self-efficacy of pregnant women with asthma regarding carrying out their asthma self-management plan?

4) Is there a difference in the knowledge, attitudes and self-efficacyof pregnant women with asthma as they advance in their pregnancies?

5) Is there a relationship between knowledge, attitudes and self-efficacy and the demographic variables of age, education, trimester of pregnancy, weeks of pregnancy, the number of pregnancies and the number of live births.

\section{DESIGN}

The research design was descriptive and exploratory. Data was collected from pregnant women with asthma at Time I, early in pregnancy and Time II, toward the end of pregnancy.

\section{SETTING}

Participants were recruited from an urban high risk pregnancy clinic. They were referred to the clinic by their primary obstetrician, at the point in their pregnancy when their asthma was either diagnosed, became acute, or other high risk conditions were identified. The clinic was located in an inner city urban area and was part of the academic medicine facility of a university medical center and medical school. The clinic serves low income pregnant women.

\section{SAMPLE}

A power analysis $(0.40$ effect size, power of 0.80 , alpha 0.005 ) determined that a sample size of 68 was appropriate for this study. A convenience sample of 101 women was recruited during their first trimester of pregnancy. Inclusion criteria were: diagnosis of asthma, the ability to understand English, and being over 18 years of age. In Illinois, pregnant adolescents can give consent for their own care during pregnancy. Exclusion criteria were: complications of pregnancy other than asthma that would likely result in prenatal hospitalization because their 
asthma would be managed by healthcare professionals during the hospitalization, diagnosis of mental retardation or psychosis to ensure ability to understand asthma and its management, and multiple gestation pregnancies because of the increased physiologic burden. Sixty-eight women completed the instruments at both Time I and Time II.

\section{PROCEDURE}

The proposal was reviewed and approved by the facilities' IRB and clinic medical director. Information sessions were given to clinic personnel and questions answered. Copies of the instruments were also presented to the personnel. The nurse manager was approached, asked and agreed to identify potential appropriate subjects. The nurse manager gave the women an information sheet about the study and requested permission to provide their names to the Research Coordinator. The Research Coordinator (RC) explained the study, answered any questions the women had, and obtained the women's signatures on the consent forms. Following informed consent, women were asked to complete the TI questionnaires at the point of first contact and provide information to facilitate follow-up for TII (point of second contact).

\section{METHODOLOGY}

\subsection{Major Study Variables}

This study contains four variables of interest: knowledge, attitudes, self-esteem and pregnancy. Since the measurement instruments for knowledge, attitudes and self-efficacy in pregnant women with asthma are adapted from other instruments or newly created, (a necessity, since there are few instruments available on the research questions) reliability and validity of each instrument is provided. Permission was obtained from the authors of the original instruments to adapt them for use in this study.

\subsection{Instrumentation}

\subsubsection{Demographics}

A demographic data sheet containing information on age, ethnic group, level of education, socioeconomic status, trimester of pregnancy, and years with asthma, previous experience with asthma in pregnancy, medications, asthma treatment and insurance was given to the subjects.

\subsubsection{Knowledge of Asthma}

The Asthma Questionnaire contains questions which assessed the respondents' knowledge of asthma. It was adapted from one that was used with mothers who had children with asthma. It contains 40 items: 38 items which employed a Likert Scale of "Agree, Disagree, Not Sure"; one item was multiple choice and one item is open ended. The multiple choice and the open ended questions did not affect the total score, but were used for information on the subject. Cronbach's Alpha Coefficient for this instrument with the study sample was 0.72 . Factor analysis using the technique of Principal Component Analysis showed that there were four principal components that explained $29 \%$ of the variance.

\subsubsection{Attitudes toward Asthma in Pregnancy}

This instrument which explores attitudes towards asthma was developed for this studyfrom the work of Fishbein and Ajzen [37]. They define attitude as "a learned predisposition to respond in a consistently favorable or unfavorable manner with respect to a given object". The questionnaire had nine questions with a three item Likert-type Scale of “Agree, Disagree or Not Sure". For the study sample, the Cronbach's Alpha Coefficient is 0.69 . Factor analysis revealed that the items loaded on three distinct components which accounted for $59 \%$ of the variance.

\subsubsection{Self-Efficacy}

Self-efficacy is measured by the Asthma Management Self-Efficacy Scale [38]. It contains 15 questions. The instrument consists of a Likert-type Scale which ranges from "Strongly Agree" to "Don't Know". Three of the 15 questions are reverse scored. The highest possible score that could be obtained is 35 and the lowest is zero. The instrument had been used previously with mothers of children with asthma, and the reliability statistic was calculated on the study sample. The Cronbach's Alpha Coefficient was 0.67. As a result of the Factor Analysis showed that five distinct components were identified whichexplained $61 \%$ of the variance.

\section{DATA ANALYSIS}

Data was analyzed using SPSS, version 17. Frequency tables and central tendencies were done on the demographic data. Frequencies, Chronbach's Alpha Coefficients, and Factor Analysis were calculated for each instrument. Paired Sample T-tests were done to compare the results of the instrument scores between Time I and Time II administration. Linear regression was done to determine the existence of any relationships among the variables.

\section{RESULTS}

\subsection{Demographic Data}

The sample at both Time I and Time II was fairly homogenous. At Time I and Time II the sample was primarily African-American, and in their early twenties. They were fairly well educated and had an income which qualified them for some form of public aid (see Table 1). 
Table 1. Demographic data Time I and II frequencies/percent.

\begin{tabular}{|c|c|c|c|c|c|}
\hline \multicolumn{6}{|c|}{$N=101$} \\
\hline \multicolumn{4}{|c|}{ Percent } & \multicolumn{2}{|c|}{ Percent } \\
\hline \multirow{2}{*}{ Variable } & \multicolumn{2}{|c|}{ Times } & \multirow{2}{*}{ Variable } & \multicolumn{2}{|c|}{ Times } \\
\hline & I & II & & $\mathrm{I}$ & II \\
\hline Marital Status & & & Income & & \\
\hline Single & 83 & 56 & $\$ 0-\$ 10,000$ & 49 & 46 \\
\hline Married & 15 & 11 & $\$ 10,001-\$ 15,000$ & 14 & 4 \\
\hline Divorced & 2 & 17 & $\$ 15,001-\$ 20,000$ & 5 & 5 \\
\hline Race & & & $\$ 20,001-\$ 30,000$ & 4 & 1 \\
\hline African-American & 89 & 60 & $\$ 30,001-\$ 35,000$ & 3 & 3 \\
\hline Caucasian & 4 & 1 & $\$ 35,001-\$ 40,000$ & 3 & 3 \\
\hline Latino & 1 & 0 & $\$ 40,001-\$ 45,000$ & 2 & 2 \\
\hline \multirow[t]{2}{*}{ Other } & 7 & 4 & $\$ 45,001-\$ 50,000$ & 0 & 1 \\
\hline & & & Over $\$ 50,000$ & 1 & 0 \\
\hline \multicolumn{6}{|l|}{ Education } \\
\hline Grammar school & 1 & 2 & Insurance & & \\
\hline High school & 37 & 20 & All Kids & 38 & \\
\hline GED & 13 & 7 & Medicaid & 30 & \\
\hline Trade & 3 & 2 & Other Aid & 32 & \\
\hline \multirow[t]{6}{*}{ College } & 40 & 27 & & & \\
\hline & & & Asthma Diagnoses & & \\
\hline & & & Mild Intermittent & 27 & \\
\hline & & & Mild Persistent & 29 & \\
\hline & & & Moderate Persistent & 21 & \\
\hline & & & Severe Persistent & 4 & \\
\hline
\end{tabular}

\subsection{Descriptive Statistics}

To answer research questions one and two and three, descriptive statistics were done. Measures of central tendencies and variance were calculated (see Table 2).

\subsection{Paired Samples T-Test}

Paired Sample $\mathrm{T}$ tests were done to determine if there was any change in the scores of the instruments from time one to time two. Results that were significant were limited to the knowledge questionnaire $(t=-4.370, p$ $-0.05)$. For the variable knowledge, there was a significant difference between Time I and Time II. The correlation was 0.789 with a significance of 0.000 . There were no significant differences between Time I and Time II on attitudes toward asthma and self-efficacy (see Table 3).
Table 2. Central tendencies.

\begin{tabular}{cccccccccc}
\hline Variable & \multicolumn{3}{c}{$N=101$} & \multicolumn{5}{c}{$N=68$} \\
\hline \multicolumn{4}{c}{ Mean Median Mode St.Dev. Mean Median Mode St.Dev. } \\
\hline \multicolumn{4}{c}{ Time I } \\
\hline Age & 26.3 & 25 & 24 & 5.792 & 26.19 & 25 & 19 & 5.373 \\
Marital & 1.21 & 1 & 1 & 0.537 & 1.21 & 1 & 1 & 0.813 \\
Status & & & & & & & & \\
Live births & 1.77 & 1 & 1 & 1.669 & 2.04 & 2 & 1 & 1.84 \\
Misc./Abor. & 1.36 & 1 & 0 & 2.133 & 1.02 & 1 & 0 & 1.046 \\
Smoke & 2 & 0.31 & 2 & 0.304 & 1.09 & 2 & 2 & 0.306 \\
\hline
\end{tabular}

Table 3. Paired samples $t$-test.

\begin{tabular}{ccccc}
\hline Variable & \multicolumn{2}{c}{$t$} & df & sig. \\
\hline Knowledge & & -4.37 & 67 & 0 \\
Attitudes & 0.679 & 0.679 & 67 & 0.5 \\
Self-efficacy & 0.883 & 0.883 & 68 & 0.38 \\
\hline
\end{tabular}

\subsection{Linear Regression}

Linear regression was done to ascertain if there was a relationship between knowledge, attitudes and self-efficacy and the demographic variables of age, education, trimester of pregnancy, weeks of pregnancy and live births. There was a significant relationship found between knowledge and education. The significance was noted at Time I and at Time II (see Table 4).

\section{DISCUSSION}

Demographic data describes an overwhelmingly poor and minority sample at both times of data collection. The participants had few job opportunities. The majority were single and on public assistance. They received prenatal care at an urban clinic administered by an academic medical center.

A preponderance of the subjects had persistent to mild/ moderate asthma. A minority of them used the peak flow meter regularly and surprisingly some still were smoking. Women were lacking in their knowledge of asthma in pregnancy at both Time I and Time II, but had gained some knowledge as they progressed in their pregnancy. Also, the more educated the women were, the greater their knowledge of asthma. This may be due to the influence of maturity, longer educational experience leading to greater understanding of the disease. Greater years of education may also lead to a better understanding of the strategies of asthma management.

\section{FUTURE RESEARCH}

There is a wealth of research opportunities available to 
Table 4. Linear regression with DV knowledge.

\begin{tabular}{cccc}
\hline & Beta & $\mathrm{t}$ & Sig. \\
\hline Time I & & & \\
Age & 0.037 & 0.276 & 0.783 \\
Ed. & 0.323 & 2.935 & 0.004 \\
1 Trim. & -0.055 & -0.294 & 0.77 \\
Preg & 0.063 & 0.328 & 0.744 \\
Num Preg & 0.106 & 0.711 & 0.479 \\
Live birth & -0.050 & 0.374 & 0.709 \\
Time II & & & \\
Age & -0.121 & 0.748 & 0.457 \\
Ed. & 0.328 & 2.669 & 0.01 \\
1 Trim. & -0.094 & -0.494 & 0.623 \\
Preg & -0.052 & -0.263 & 0.794 \\
Num Preg & 0.19 & 1.087 & 282 \\
Live birth & -0.085 & -0.589 & 0.558 \\
\hline
\end{tabular}

explore asthma and pregnancy. Researchers may want to question what nursing educational intervention increases women's knowledge of asthma during pregnancy. Appropriate content, mode, and timing of educational activities are also research topics of interest. Women's feelings about asthma and pregnancy and the effectiveness of an educational intervention are also valuable research questions to be considered.

\section{NURSING IMPLICATIONS}

The ultimate goal of asthma care during pregnancy is to avoid maternal hypoxic episodes and thereby maintain adequate oxygenation of the fetus [9]. Nurses have an essential role to play in the care of pregnant patients with asthma. As members of the health care team, they assist patients to navigate the various aspects of specialty medical and nursing care. Physical, educational and emotional needs are assessed and nursing interventions implemented.

\subsection{History}

Assessment begins with a thorough history which includes not only pregnancy-related data, but asthma data as well. Questions for data gathering include when asthma symptoms first began, pre-pregnancy management of asthma, the average length of time an attack lasts, what triggers are known to produce an attack, the severity of an attack, and specific measures used during an astma attack. Information regarding emergency room visits and hospital admissions is also solicited. A thorough discussion includes what medications are being taken, those that are most effective and what treatments are most successful. A review of if or how the asthma symptoms and treatments affect the pregnancy or vice versa is also appropriate.

\subsection{Physical Examination}

Heart and lung sounds along with techniques for maternal and fetal assessment are also utilized for comprehensive care. The lungs are assessed for any adventitious sounds and heart rate and rhythm are evaluated for any untoward symptoms associated with asthma or the pregnancy. Fetal heart rate and fundal height are done as per routine. Other obstetrical assessments (ultrasound, biophysical profile, blood tests) may be done as needed.

\subsection{Nursing Interventions}

\subsubsection{Physiological Interventions}

Possible nursing interventions depend upon the severity of asthma, the trimester of pregnancy and the presence of asthma or pregnancy complications. Interventions include administering and evaluating the results of the peak flow meter and pulse oximetry. If the patient's condition is unstable at the time of the visit or admission to the emergency room, arterial blood gases may also be ordered. Lab tests such as urinalysis, urine culture and $\mathrm{CBC}$ and differential may also be ordered, especially if there is a suspicion of a concomitant infection. Referral to a pulmonologist or perinatologist may be given with necessary contact information. Pulmonary function testing may be ordered. This is especially useful if baseline information is available from prior to the pregnancy.

\subsubsection{Emotional Interventions}

Feelings about being pregnant with the addition of asthma are important topics [39]. Examination of feelings is done in the initial and subsequent prenatal visits. Interventions include therapeutic listening in which patients can vent their feelings without fear of judgment. Referrals to support groups, and to counselors and nurses specializing in the area, may also be appropriate, especially if accessible and low cost. In some cases it may be of importance to identify any significant emotional triggers for attacks or altered responses to treatment when there are underlying emotional elements known to affect the patient's disease.

\subsubsection{Educational Interventions}

Educational assessment begins with asking what the patient already knows about how asthma affects pregnancy and vice versa. After the initial assessment, education interventions begin. Print media, videos, social networking, and web sites for support groups and educational groups are provided to the patient at the appropriate 
reading level. The content of each should be discussed with the patient and the questions answered. Besides the disease itself, and its effects on pregnancy, medications, peak flow meters and effects of smoking (in general, and in pregnancy) should be reviewed and problem solutions found if necessary. Other educational interventions are directed toward known individual triggers. For example, an individual may be a non-smoker, but engaged in activities or employment that put them at risk for symptoms from second-hand smoke. Similarly, if allergens have been a primary trigger, information about low cost options for allergy-proofing the sleeping area might be provided. Regardless of income level, or frequency of symptoms, educational interventions must be tailored to meet individual patient needs. In many cases, education will need to be provided "just in time" or even repeated when the patient is able to focus on the material. Nurses frequently offer patient education and assume that patients have learned what has been presented. Recent experience with another patient population validated that one of the major barriers to effective patient education is the nurse or other health care provider's belief that they know what the patient needs to know when in fact, patients have shared that they can't hear professional advice until their concerns have been heard. This finding has significant implications for the way patient education is designed.

\section{CONCLUSION}

Asthma is a globally prevalent disease. It affects all ages and races. Research findings of the current study indicate that although some women in the study were knowledgeable about their disease during pregnancy, many were not. Therefore, asthma education tailored to the effects of pregnancy on asthma and the effects of asthma on pregnancy is an essential component of patient education. Indeed, previous research has shown that asthma education is also necessary for asthma self-management for pregnant women [9,18-23]. Since knowledge increased as pregnancy progressed, and changes of pregnancy may have altered symptoms of asthma, education needs to be continuous and seamless throughout the pregnancy. The women's attitudes were generally positive toward having asthma in pregnancy. A positive attitude can be used to motivate women to seek and continue asthma education during the childbearing period, resulting in self-efficacy toward managing the disease. All three variables combine to culminate in successful self-management of asthma in pregnancy.

\section{REFERENCES}

[1] American Lung Association Epidemiology and Statistics Unit, Research and Program Services Division (2011)
Trends in asthma morbidity and mortality. http://www.lung.org/finding-cures/our-research/epidemio logy-and-statistics-rpts.html

[2] Guthrie, C.M. and Tingen, M.S. (2002) Asthma-A case study review of pathophysiology and management strategies. Journal of the American Academy of Nurse Practitioners, 14, 457-461. http://dx.doi.org/10.1111/j.1745-7599.2002.tb00076.x

[3] National Heart, Lung, and Blood Institute (2007) Guidelines for the diagnosis and treatment of asthma. National Asthma Education and Prevention Program Expert Panel Report 3, US Department of Health and Human Services, NIH Publication Number 08-5846.

[4] Herman, E.J., Garbe, P.L. and McGeehan, M.A. (2010) Assessing community-based approaches to asthma control: The controlling asthma in American cities project. Journal of Urban Health: Bulletin of the New York Academy of Medicine, 88, 1-6.

[5] Northridge, M.E., Meyer, I.H. and Dunn, L. (2002) Overlooked and under served in Harlem: A population based survey of adults with asthma. Environmental Health Perspectives Supplements, 110, 217, 220.

http://web16epnet.com

[6] Whitman, S., Williams, C. and Shah, A.M. (2004) Improving community health survey, report. http://www.sinai.org/urban/originalresearch/rwj/index.asp

[7] Moorman, J.E., Rudd, R.A., Johnson, C.A., King, M., Minor, P., Bailey, C., Scalia, M.R. and Akinbam, L.J. (2007) Surveillance summaries. MMWR/CDC, 56, 1-46.

[8] Kwon, H.L., Triche, E.W., Belanger, K. and Bracken, M.B. (2006) The epidemiology of asthma during pregnancy: Prevalence, diagnosis and symptoms. Immunology and Allergy Clinics of North America, 26, 29-32. http://dx.doi.org/10.1016/j.iac.2005.11.002

[9] Dombrowski, M.P. and Schatz, M. (2010) Asthma in pregnancy. Clinical Obstetrics and Gynecology, 33, 301310. http://dx.doi.org/10.1097/GRF.0b013e3181de8906

[10] Kallen, B., Rydhstroem, H. and Aberg, A. (2000). Asthma during pregnancy: A population based study. European Journal of Epidemiology, 16, 167-171. http://dx.doi.org/10.1023/A:1007678404911

[11] Liu, S., Wen, S.W., DeMissie, K., Marcoux, S. and Kramer, M.S. (2001) Maternal asthma and pregnancy outcomes: A retrospective cohort study. American Journal of Obstetrics and Gynecology, 184, 90-96. http://dx.doi.org/10.1067/mob.2001.108073

[12] Wen, S.W., DeMissie, K. and Liu, S. (2001) Adverse outcomes in pregnancies of asthmatic women: Results from a Canadian population. Annals of Epidemiology, 11, 7-12. http://dx.doi.org/10.1016/S1047-2797(00)00077-6

[13] Stach, S.L. (2000) Improving self-care in adults with asthma using peak expiratory flow rate home monitoring. Journal of the American Academy of Nurse Practitioners, 12, 69-70. http://dx.doi.org/10.1111/j.1745-7599.2000.tb00285.x

[14] Scherer, Y.K. and Bruce, S. (2001) Knowledge, attitudes and self-efficacy and compliance with medical regimen, number of emergency department visits, and hospitaliza- 
tions in adults with asthma. Heart and Lung, 30, 250-257. http://dx.doi.org/10.1067/mhl.2001.116013

[15] Stelmach, W., Majak, P., Jerzynska, J. and Stelmach, I. (2005) Early effects of asthma prevention program on asthma diagnosis and hospitalization in an urban population of Poland. Allergy, 60, 606-610. http://dx.doi.org/10.1111/j.1398-9995.2005.00773.x

[16] Butz, A.M., Syron, L., Johnson, B., Spaulding, J., Walker, M. and Bollinger, M.E. (2005) Home based asthma selfmanagement education for inner-city children. Public Health Nursing, 22, 189-199.

http://dx.doi.org/10.1111/j.0737-1209.2005.220302.x

[17] Murphy, V.E., Gibson, P.G., Talbot, P.I., Kessell, C.G. and Clifton, V.L. (2005) Asthma self-management skills and the use of asthma education during pregnancy. European Respiratory Journal, 26, 435-441. http://dx.doi.org/10.1183/09031936.05.00135604

[18] Wigal, J.K., Stout, C. Brandon, M. Winder, J., McConnaughy, K., Creer, T. and Kostes, H. (1993) The knowledge, attitude and self-efficacy asthma questionnaire. Chest, 104, 1144-1148. http://dx.doi.org/10.1378/chest.104.4.1144

[19] Benninger, C. and McCallister, J. (2010) Asthma in pregnancy reading between the lines. The Nurse Practitioner, 35, $10-19$ http://dx.doi.org/10.1097/01.NPR.0000369937.32234.05

[20] Stone, J.S. and Nelson-Piercy, C. (2009) Respiratory disease in pregnancy. Obstetrics, Gynecology and Reproductive Medicine, 20, 14-21. http://dx.doi.org/10.1016/j.ogrm.2009.10.003

[21] Tamasi, L., Horvath, I., Bohacs, A., Muller, V., Losonczy, G. and Schatz, M. (2011) Asthma in pregnancy-Immunological changes and clinical management. Respiratory Medicine, 105, 159-164. http://dx.doi.org/10.1016/j.rmed.2010.11.006

[22] Schatz, M. and Dombrowski, M.P. (2009) Asthma in pregnancy. The New England Journal of Medicine, 360, 1862-1869. http://dx.doi.org/10.1056/NEJMcp0809942

[23] Weis, K.L. (2003) Asthma management across the life span: The childbearing woman with asthma. The Nursing Clinics of North America, 38, 665-674. http://dx.doi.org/10.1016/S0029-6465(03)00105-1

[24] Murphy, V.E. and Gibson, P.G. (2010) Asthma and rhinitis in pregnancy. Allergy Frontiers: Therapy and Prevention, 5, 485-497.

[25] Powrie, E.O., Larson, L. and Miller, M. (2006) Managing asthma in expectant mothers. Treatments in Respiratory Medicine, 5, 1-10. http://dx.doi.org/10.2165/00151829-200605010-00001

[26] Richardson, H.M. (1991) The perceptions of Canadian young adults with asthma of their health teaching/learning needs. Journal of Advanced Nursing, 16, 447-453. http://dx.doi.org/10.1111/j.1365-2648.1991.tb03435.x
[27] Beckmann, C.A. (2002) A descriptive study of women's perceptions of their asthma during pregnancy. American Journal of Maternal Child Nursing, 27, 98-102. http://dx.doi.org/10.1097/00005721-200203000-00009

[28] Janson-Bjerklie, S.L. and Pardini, K. (1988) Relationship of panic-fear symptomatology to patterns of asthma selfcare in emotionally triggered asthma. American Review of Respiratory Diseases, 137-117.

[29] Lehrer, P.M., Isenberg, S. and Hochron, S.M. (1993) Asthma and emotion: A review. Journal of Asthma, 30, 5-21. http://dx.doi.org/10.3109/02770909309066375

[30] Mancuso, C.A., Sayles, W. and Allegrante, J.P. (2010) Knowledge, attitude, and self-efficacy in asthma selfmanagement and quality of life. Journal of Asthma, 47, 883-888 http://dx.doi.org/10.3109/02770903.2010.492540

[31] Arnold, R., Ranchor, A.V., DeJongste, M.J., Koeter, G.H., Ten Hacken, N.H., Aalbers, R. and Sandeman, R. (2005) The relationship between self-efficacy and self-reported physical functioning in chronic obstructive pulmonary disease and heart failure. Behavioral Medicine, 31, 107115. http://dx.doi.org/10.3200/BMED.31.3.107-115

[32] Cummings, E., Turner, P., Walters, H., Baker, R.W., Robinson, A. and Courtney-Prat, H. (2006) Pathways home project: Patient self-management and self-efficacy through the deployment of ICS. BLED 2006 Proceedings, Paper 12. http://a/se/.aisnet.org/bled2006/12

[33] Shegogg, R., Bartholomew, K. Parcel, G.S., Sockrider, M.M., Masse, L. and Abramson, S. (2001) Impact of a computer-assisted education program on factors related to asthma self-management behavior. Journal of the American Medical Informatics Association, 8, 49-61. http://dx.doi.org/10.1136/jamia.2001.0080049

[34] Clark, N.M., Valerio, M.A. and Gong, Z.M. (2008) Self-regulation and women with asthma. Current Opinion in Allergy and Clinical Immunology, 8, 222-227. http://dx.doi.org/10.1097/ACI.0b013e3282fe9d05

[35] Bodenheimer, T., Lorig, K., Holman, H. and Grumbach, K. (2002) Patient self-management of chronic disease in primary care. Journal of the American Medical Association, 288, 2469-2475. http://dx.doi.org/10.1001/jama.288.19.2469

[36] Orem, D.E. (2001) Nursing: Concepts of practice. 5th Edition. Mosby-Yearbook, Inc., St. Louis.

[37] Fishbein and Ajzen (1975) Attitude and related problems in science education. John Wiley \& Sons Inc., Hoboken.

[38] Telleen, S. (2007) Asthma management self-efficacy scale. www.sinai.org

[39] Comerford, M.F., Moos, M.K. and Curtis, M. (2006) The history of preconception care: Evolving guidelines and standards. Maternal Child Health Journal, 10, 43-52. http://dx.doi.org/10.1007/s10995-006-0087-x 